\title{
Low Perioperative Prealbumin Level Predicts Early Recurrence After Curative Pulmonary Resection for Non-small Cell Lung Cancer
}

\author{
Hideki Kawai
}

Published online: 27 February 2013

(C) Société Internationale de Chirurgie 2013

Thank you for your interest in our paper.

As pointed out, the dichotomization of continuous variables is a poor approach, although it is quite frequently used. I understand this issue. Instead of this method, I would prefer to employ a multiple linear regression strategy or structural equation model, which is more suitable for this type of statistical analysis [1, 2]. However, these methods require large numbers. This is a limitation of the present study.

This study demonstrated nutritional status to be a critical factor, accounting for its influence on prognosis during the perioperative period of non-small cell lung cancer. In the clinical setting, a simple and convenient parameter is important for evaluation. As to this matter, the present study is important and provides practical information.
Clearly, further study is needed with an increased number of subjects and we would like to verify the usefulness of this parameter by employing a more appropriate statistical method, as noted above, for evaluation.

\section{References}

1. Cohen J, Cohen P, West SG, Aiken LS (2003) Applied multiple regression/correlation analysis for the behaviorial sciences. Lawrence Elbaum Associates, London

2. Marsh HW, Wen Z, Hau KT (2004) Structural equation models of latent interactions: evaluation of alternative estimation strategies and indicator construction. Psychol Methods 9(3):275-300

H. Kawai $(\bowtie)$

Department of Thoracic Surgery, Akita Red Cross Hospital,

Akita, Japan

e-mail: kawai-h@akita-rch.com 